\title{
Study of Hypochlorite Reduction Related to the Sodium Chlorate Process
}

\author{
Kristoffer Hedenstedt $^{1,2}$ • Adriano S. O. Gomes ${ }^{1,2} \cdot$ Michael Busch $^{2,3} \cdot$ Elisabet Ahlberg $^{2}$
}

Published online: 21 April 2016

(C) The Author(s) 2016. This article is published with open access at Springerlink.com

\begin{abstract}
Reduction of hypochlorite is the most important side reaction in the sodium chlorate reactor leading to high energy losses. Today chromate is added to the reactor solution to minimize the hypochlorite reduction but a replacement is necessary due to health and environmental risks with chromate. In order to understand the effect of different substrates on the hypochlorite reduction, $\alpha$-FeOOH, $\gamma$ - $\mathrm{FeOOH}, \mathrm{Cr}_{2} \mathrm{O}_{3}$ and $\mathrm{CrOH}_{3}$ were electrodeposited on titanium and subjected to electrochemical investigations. These substances are commonly found on cathodes in the chlorate process and can serve as model substances for the experimental investigation. The mechanism of hypochlorite reduction was also studied using DFT calculations in which the reaction at $\mathrm{Fe}(\mathrm{III})$ and $\mathrm{Cr}$ (III) surface sites were considered in order to single out the electrocatalytic properties. The experimental results clearly demonstrated that the chromium films completely block the reduction of hypochlorite, while for the iron oxyhydroxides the process can readily occur. Since the electrocatalytic properties per se were shown by the DFT calculations to be very similar for $\mathrm{Fe}(\mathrm{III})$ and $\mathrm{Cr}$ (III) sites in the oxide matrix, other explanations for the blocking ability of chromium films are addressed and discussed in the context of surface charging, reduction of anions and conduction in the deposited films. The main conclusion is that the combined effect of electronic properties and
\end{abstract}

Elisabet Ahlberg ela@chem.gu.se

1 AkzoNobel Pulp and Performance Chemicals, SE-445 80 Bohus, Sweden

2 Department of Chemistry and Molecular Biology, University of Gothenburg, Kemigården 4, SE-412 96 Gothenburg, Sweden

3 Present address: Laboratory for Computational Molecular Design, Institut des Sciences et Ingénierie Chimiques, Ecole Polytechnique Fédérale de Lausanne, CH-1015 Lausanne, Switzerland reduction of negatively charged ions can explain the reduction kinetics of hypochlorite and the effect of chromate in the chlorate process.

Keywords DFT calculations $\cdot \alpha-\mathrm{FeOOH} \cdot \gamma-\mathrm{FeOOH}$. Electrodeposition $\cdot \mathrm{Cr}_{2} \mathrm{O}_{3} \cdot \mathrm{Cr}(\mathrm{OH})_{3}$

\section{Introduction}

Sodium chlorate is an important industrial chemical with roughly $3.6 \times 10^{6}$ metric ton of the product produced annually worldwide. Its main usage is for chlorine dioxide production used in elemental chlorine free (ECF) pulp bleaching but also for water purification purposes and as emergency oxygen supply in air crafts. Today sodium chlorate is produced by an electrosynthesis route where sodium chloride is oxidized to sodium chlorate in either continuous or batch wise plants. The process is highly energy consuming, around $4250-5500 \mathrm{kWh}$ is used to produce 1 ton of the product [1]. The energy consumption is intrinsically related to the performance of the electrodes. Surface analysis has shown that common corrosion products formed in the process are $\alpha$ - and $\gamma$ $\mathrm{FeOOH}$ and that these corrosion products behave differently, with $\alpha-\mathrm{FeOOH}$ showing better performance than $\gamma$-FeOOH (Hedenstedt et al., in review).

In order to minimize losses in the process sodium dichromate is added to the electrolyte. Its use is well known since the end of the 19th century and addition of sodium dichromate to the process increases the current efficiency significantly [2-4]. Work has been done to understand the role of dichromate in the process and it appears to be reduced forming a thin $\mathrm{Cr}$ (III) film on the cathode. This film hinders the reduction of hypochlorite and chlorate while the desired hydrogen evolution 
reaction (HER) readily takes place. The film consists of $\mathrm{Cr}$ (III) hydrous oxide or hydroxide, which is oxidized back to chromate when the current is switched off $[5,6]$. Other benefits from chromate addition are $\mathrm{pH}$ buffering and corrosion inhibition on the steel cathodes used [4, 7-17]. However, sodium dichromate is listed in the Annex XIV under REACH [18], which means that without authorization it is forbidden to use after the sunset date in late 2017. Efforts have been made to exchange chromium with molybdenum, yttrium and other rare earth metals but so far nothing has proven good or long-term stable enough to replace chromate [19-23]. Recently, it was shown that adding trivalent chromium to the electrolyte will be sufficient to in situ form the desired species [24]. However, to entirely remove chromium from the process and find a replacement product, it is crucial to fully understand the role of chromium.

The present paper focuses on the reduction of hypochlorite on separately deposited $\alpha$ - $\mathrm{FeOOH}, \gamma$ - $\mathrm{FeOOH}$, chromium (III) oxide and hydroxide. These compounds are present on cathodes in the chlorate process and to obtain fundamental knowledge about the reduction of hypochlorite it is important to study these substrates individually. Additionally, DFT calculations were performed to obtain a molecular understanding of the reduction mechanism. The combined experimental and theoretical results are used to discuss the prevailing explanations for differences in hypochlorite reduction depending on substrate and the beneficial effect of chromate on the energy efficiency in the chlorate process.

\section{Experimental and Calculations}

\section{Electrode Preparation}

$1 \mathrm{~cm}^{2}$ discs were prepared from titanium grade 1 . Before electrodeposition of $\alpha-\mathrm{FeOOH}, \gamma-\mathrm{FeOOH}, \mathrm{Cr}_{2} \mathrm{O}_{3}$ and $\mathrm{Cr}(\mathrm{OH})_{3}$, the discs were polished with 4000 grit $\mathrm{SiC}$ paper and etched $10 \mathrm{~s}$ in $5 \mathrm{wt} \%$ hydrofluoric acid. Deposition of $\alpha$-FeOOH and $\gamma-\mathrm{FeOOH}$ was made potentiostatically onto the titanium disc substrates according to the method described by Martinez et al. [25]. For the deposition of $\mathrm{Cr}_{2} \mathrm{O}_{3}$ and $\mathrm{Cr}(\mathrm{OH})_{3}$, the method described by Aguilar et al. [26] was followed. All chemicals were of analytical grade from Fluka and prepared with $18 \mathrm{M} \Omega$ Milli-Q water. The electrodes were characterized with X-ray diffraction (XRD) and scanning electron microscopy with energy dispersive X-rays (SEM/ EDX). Pure titanium grade 1 and mild steel (EN 10277-22008) from Permascand were used for comparison. The Xray diffractometer was a Siemens D5000 with BraggBrentano setup and $\mathrm{CuK} \alpha=1.5418 \AA$ radiation. Scanning electron microscopy with energy dispersive $\mathrm{X}$-rays was made with a Leo Ultra 55 FEG SEM complemented with an Oxford Inca EDX system.

\section{Electrochemical Setup}

Electrochemical kinetic experiments were made with a three electrode cell using a Gamry Reference 600 potentiostat. A circular platinum mesh electrode was used as counter electrode and a double junction $\mathrm{Ag} / \mathrm{AgCl}$ with $3 \mathrm{M} \mathrm{KCl}$ was used as reference electrode, $\mathrm{E}^{0}=0.210 \mathrm{~V}$ vs. nhe. The electrolyte was $0.200 \mathrm{M} \mathrm{Na}_{2} \mathrm{SO}_{4}$ with $\mathrm{pH}$ set to 11.0 with $\mathrm{NaOH}$ using a Metrohm $827 \mathrm{pH}$ meter. Sodium hypochlorite from Fluka, reagent grade, was added when needed. The electrolyte was purged with nitrogen for at least $30 \mathrm{~min}$ before and kept under nitrogen flow during the experiments. The concentration of hypochlorite was determined by iodometric titration with sodium thiosulphate.

\section{Computational Details}

The DFT calculations were performed using CASTEP (version: 5.0) [27] as implemented in the Materials Studio suite [28]. A $\Gamma$-point k-point set in combination with a plane-wave cut-off energy of $400 \mathrm{eV}$ and the PBE [29] Generalized Gradient Approximation (GGA) functional was used. The core electrons were modelled by an ultrasoft pseudopotential [30]. Following previous work a high spin electronic configuration in combination with a ferromagnetic coupling between the transition metal sites was assumed [31, 32]. The electrochemistry was modelled using a binuclear $\mathrm{Cr}$ or $\mathrm{Fe}$ site embedded into a $\mathrm{MgO}_{\mathrm{y}}(\mathrm{OH})_{\mathrm{z}}$ test rig. The energetics of all electrochemical steps were calculated using the tyrosine/tyrosyl radical (TyrOH/TyrO') redox couple as hydrogen sink. The electrochemical potential of this reference system has been experimentally determined to be $1.22 \mathrm{~V}$ vs nhe at $\mathrm{pH} 2$ [33]. The test rig has been designed to reproduce central aspects of the active site (oxidation states and coordination sphere) at minimal costs. The validity of this simple yet efficient model system has been shown in a series of studies concerning electrochemical water splitting. It was found that the test rig system is able to reproduce trends with a semi-quantitative accuracy $[31,34-36]$.

\section{Results}

\section{Surface Characterization}

$\alpha-\mathrm{FeOOH}$ and $\gamma-\mathrm{FeOOH}$

The deposition of $\gamma$-FeOOH was made at $+1.00 \mathrm{~V}$ vs. $\mathrm{Ag} /$ $\mathrm{AgCl}$ and a total of 4 coulombs was passed during the process. The SEM image shows a homogeneous surface with clear flake like $\gamma$-FeOOH crystals and only $\mathrm{Fe}, \mathrm{O}$ and Ti were found in the EDX analysis, Fig. 1. The X-ray diffractogram confirmed the presence of $\gamma-\mathrm{FeOOH}$ with preferred orientation 
of the (101) and (411) reflections, but also $\alpha$-FeOOH could be detected, Fig. 1. The XRD method for analysing crystalline phases is based on randomized ordering in the crystal structure to allow reflections from every possible lattice. However, for electrodeposited $\gamma$-FeOOH clear ordering of crystals on the surface is obtained and all lattices are therefore not visible in the diffractogram. Deposited material that was scraped off the electrode and analysed as a powder clearly show that the main product is indeed $\gamma$-FeOOH [].

Figure 2 shows the corresponding results for $\alpha-\mathrm{FeOOH}$. The deposition was made at $-0.150 \mathrm{~V}$ vs. $\mathrm{Ag} / \mathrm{AgCl}$ and a total of 4 coulombs was passed during the process. The SEM image shows a completely different surface compared with the $\gamma$ phase. The surface is much coarser and has no well-defined crystals. Also in this case only Fe, O and Ti were found with EDX. The X-ray diffractogram confirmed the presence of the $\alpha$-phase but also some $\gamma$-FeOOH could be detected.

The XRD analyses showed that the phases were not entirely pure but both $\alpha$ - and $\gamma$-phases coexisted. Since XRD is only a qualitative method, if an internal standard is not used, it is not possible to determine the composition. However, the SEM images can give additional information. Figure 1 shows well defined crystals of $\gamma$-FeOOH and very little of other material, while Fig. 2 shows very little of $\gamma$-FeOOH crystals. This, in combination with differences in the cyclic voltammetry for the two different electrodes, Fig. 3, ensures that the majority of the phases are the expected ones and are controlling the electrochemical properties of the electrodes. It has been shown by in situ Mössbauer spectroscopy that initially the reduction takes place within the original structure and only at more negative potentials a phase transformation occurs [37]. The process is reversible and upon re-oxidation the original compounds are formed [37]. Figure 3 shows the redox properties of $\gamma$ $\mathrm{FeOOH}$ and $\alpha-\mathrm{FeOOH}$ within a restricted potential range to avoid phase transformation and hydrogen evolution.

\section{$\mathrm{Cr}_{2} \mathrm{O}_{3}$ and $\mathrm{Cr}(\mathrm{OH})_{3}$}

Following the method described by Aguilar [26], $\mathrm{Cr}_{2} \mathrm{O}_{3}$ and $\mathrm{Cr}(\mathrm{OH})_{3}$ form very different deposits observable with naked eyes. The first appear as a dark and rough layer and the second as a greyish smooth surface. After deposition, $\mathrm{Cr}_{2} \mathrm{O}_{3}$ appears as a black layer, strongly attached to the surface, which allows experiments to be done with rotation of the electrode. If dried, the coverage is brittle and easily detaches from the Ti substrate. SEM imaging was used to characterize the morphology of the electrodeposited $\mathrm{Cr}_{2} \mathrm{O}_{3}$ and $\mathrm{Cr}(\mathrm{OH})_{3}$ materials, Fig. 4. The surface composition was determined with EDX and is given in Table $1 . \mathrm{Cr}_{2} \mathrm{O}_{3}$ electrodeposition resulted in flake-like crystals, with sizes around $2 \mu \mathrm{m}$, Fig. 4 (left), while $\mathrm{Cr}(\mathrm{OH})_{3}$ appears as an amorphous material on the
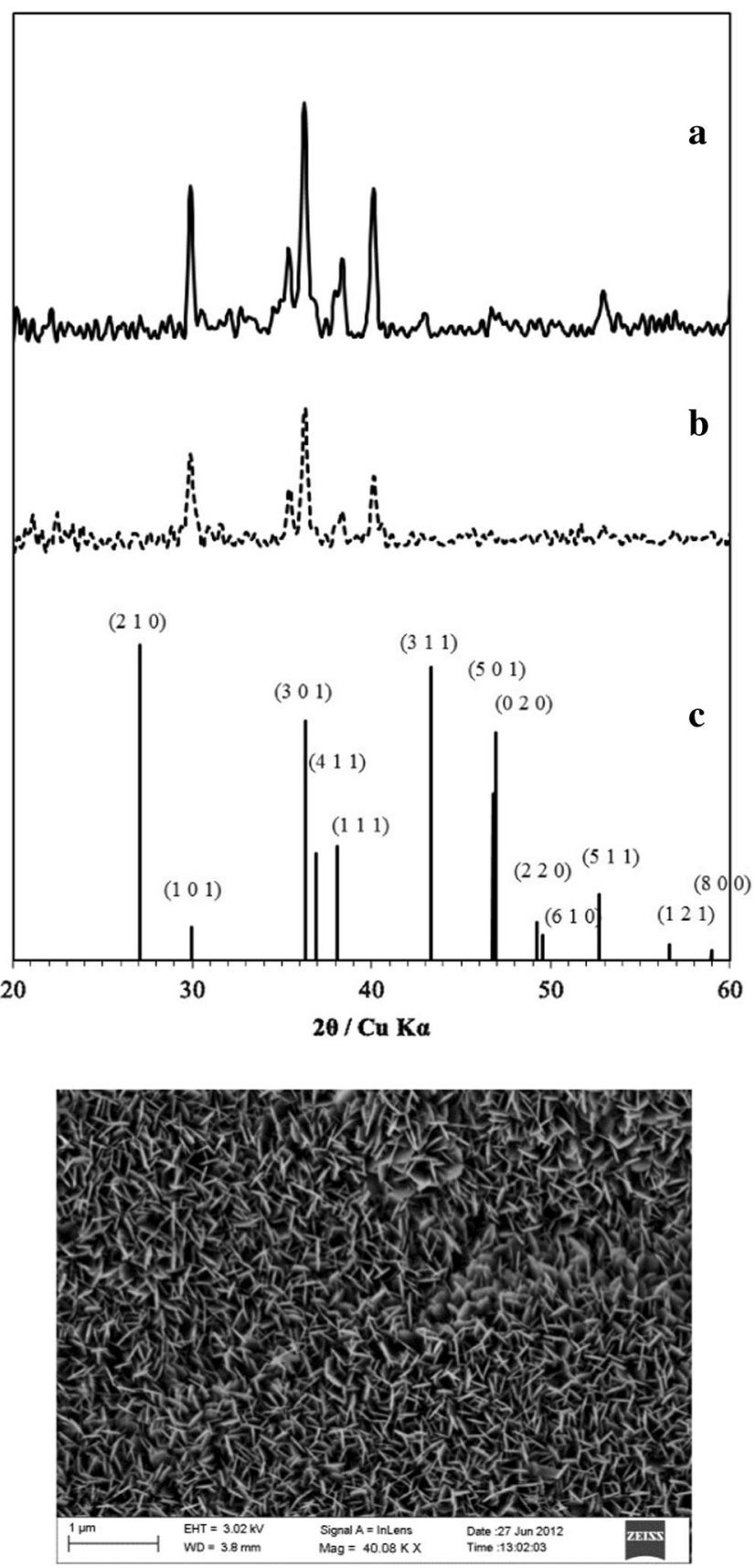

Fig. $1 \gamma$-FeOOH deposited onto titanium substrate. XRD analysis of the electrode before (a) and after experiments (b). (c) shows the lepidocrocite $(\gamma-\mathrm{FeOOH})$ standard (PDF 00-044-1415) and below the SEM image of the electrode

surface, Fig. 4 (right). As can be seen in Table 1, the ratio $\mathrm{Cr}: \mathrm{O}$ was found to be about $2: 3$ and $1: 3$ for $\mathrm{Cr}_{2} \mathrm{O}_{3}$ and $\mathrm{Cr}(\mathrm{OH})_{3}$, respectively. This is a good indication of the composition. Since the EDX analysis extends deep in the sample depending on the electron acceleration $(\mathrm{kV})$, the amount of substrate detected can be used to compare the thickness of two different layers. Table 1 shows that the amount of Ti detected is much higher for the surface 

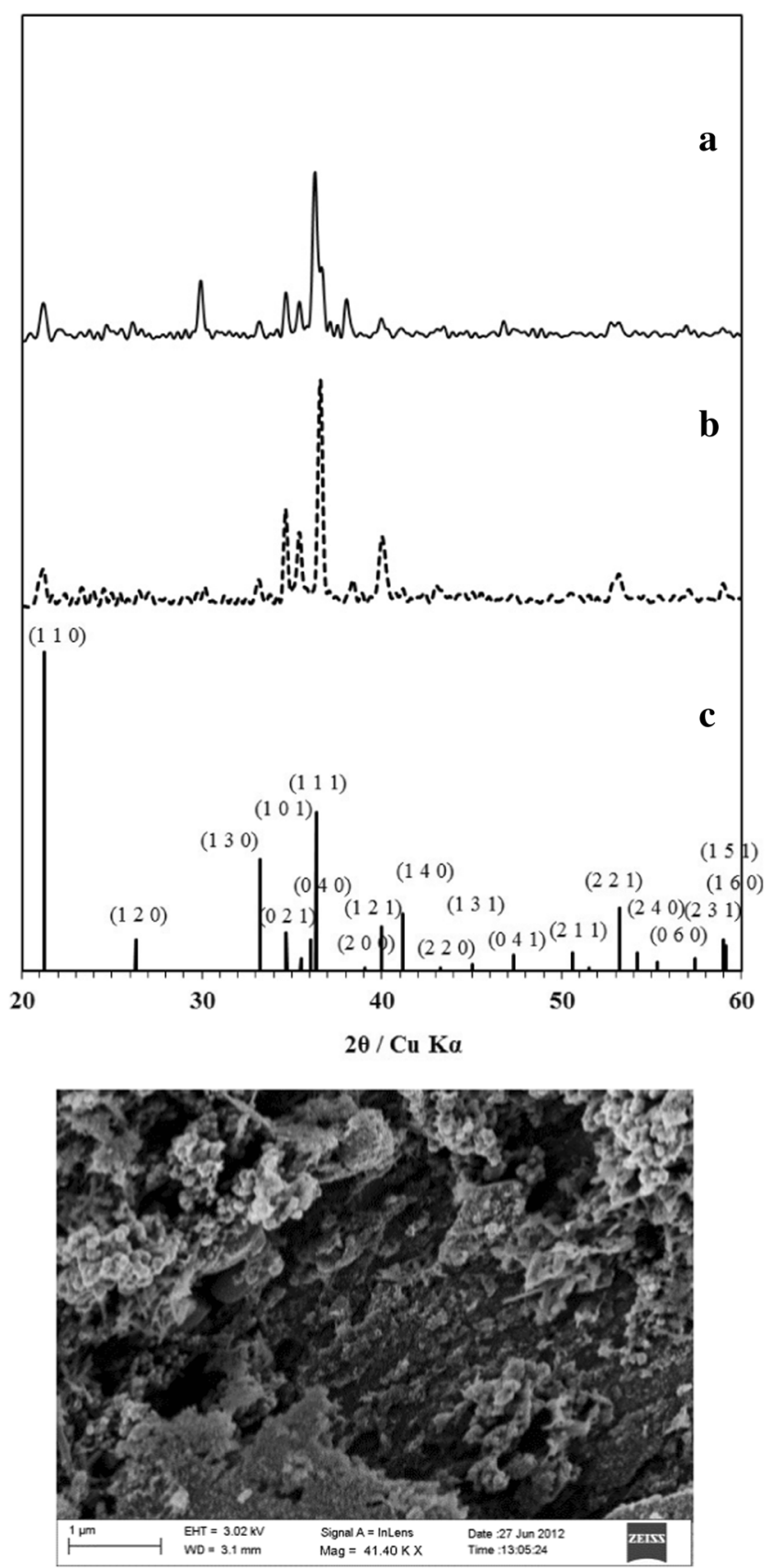

Fig. $2 \alpha$-FeOOH deposited onto titanium substrate. XRD analysis of the electrode before (a) and after experiments (b). (c) shows the goethite $(\alpha-$ FeOOH) standard (PDF 00-029-0713) and below the SEM image of the electrode

covered with $\mathrm{Cr}(\mathrm{OH})_{3}$, which indicates a thinner layer compared with $\mathrm{Cr}_{2} \mathrm{O}_{3}$.

No clear X-ray diffraction patterns were obtained for the deposits, which is in line with previous findings [26, 38].

\section{Reduction of Hypochlorite}

The electrochemical evaluations were performed in sodium sulphate electrolyte adjusted to $\mathrm{pH} 11$. Sodium

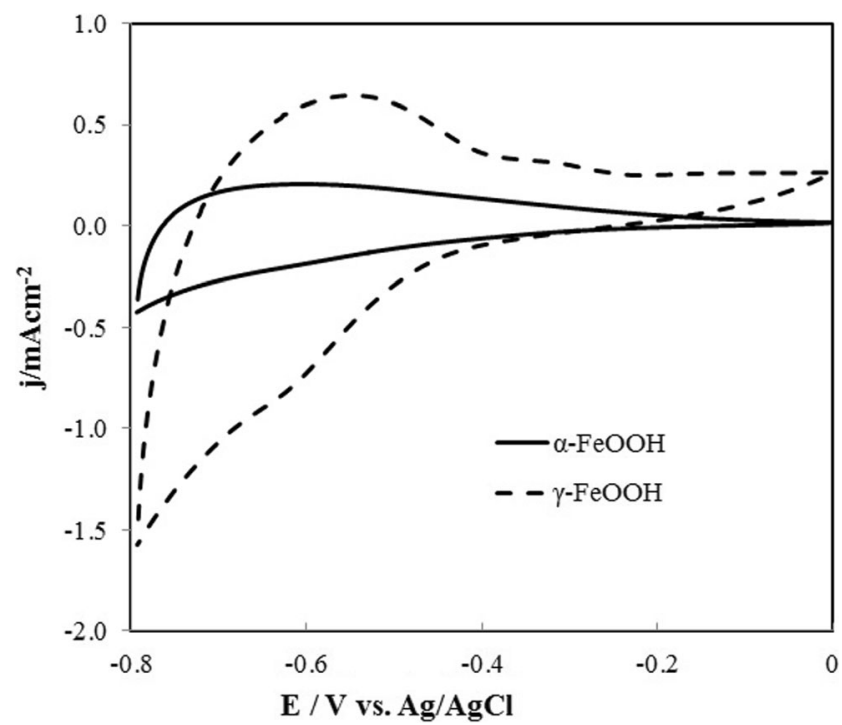

Fig. 3 Cyclic voltammerty for the $\alpha$-FeOOH and $\gamma$-FeOOH electrodes in $0.2 \mathrm{M} \mathrm{Na}_{2} \mathrm{SO}_{4}, \mathrm{pH} 11$. Sweep rate $5 \mathrm{mVs}^{-1}$ and rotation rate $3000 \mathrm{rpm}$

sulphate was chosen due to its inertness and to control all sources of chlorides, which will form hypochlorite at the anode if present. The $\mathrm{pH}$ in the sodium chlorate cells during operation is usually set to somewhere between 6.1 and 7. However, at the cathode and close to its surface, the solution is alkaline due to the formation of $\mathrm{OH}^{-}$from the hydrogen evolution reaction (HER). To ensure the alkalinity and simulate operating conditions during these short-term experiments with high convection from the rotating disc electrode, $\mathrm{pH}$ of the electrolyte was set to 11.

For evaluation of the kinetics, linear sweeps with varying rotation rates were performed on the different materials. However, no rotation rate dependence was observed and the kinetic evaluation has therefore been made at constant rotation rate.

\section{$\alpha-\mathrm{FeOOH}$ and $\gamma-\mathrm{FeOOH}$}

Figure 5 shows positive going polarization sweeps for hypochlorite reduction at different surfaces. The hypochlorite reduction takes place in parallel with surface reactions related to redox properties of the iron oxy-hydroxides, see Fig. 3. For the mild steel electrode a mixed potential is obtained where the oxidation reaction is the dissolution of iron and the cathodic reaction is hypochlorite reduction. The data for Ti, $\alpha$ - and $\gamma$-FeOOH as substrates were fitted to an irreversible one electron transfer while for mild steel also an anodic electron transfer was included in the fitting. In the inset to Fig. 5, the logarithm of the current is plotted as a function of potential for easy comparison of Tafel slopes and activity. The fittings are also shown in the inset and for all surfaces except pristine Ti the Tafel slopes are about $120 \mathrm{mV} /$ decade for the reduction of 
Fig. 4 Scanning electron microscopy of $\mathrm{Cr}_{2} \mathrm{O}_{3}$ (left) and $\mathrm{Cr}(\mathrm{OH})_{3}$ (right) electrodeposited onto titanium substrate
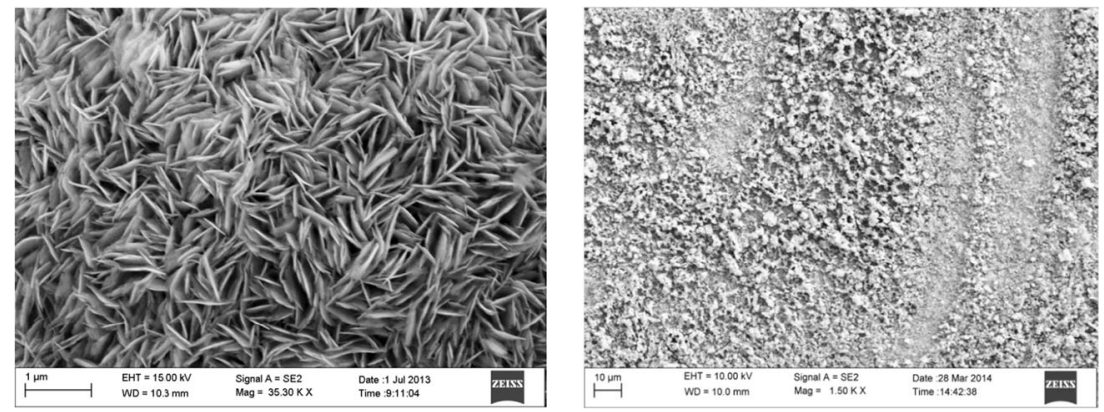

hypochlorite. These results show that the first electron transfer is rate limiting with a transfer coefficient close to 0.5. Also for the titanium substrate, with a Tafel slope of $160 \mathrm{mV} /$ decade, the first electron transfer is rate limiting but with a somewhat smaller transfer coefficient. In this potential region, the most active substrate is the newly polished mild steel followed by $\alpha-\mathrm{FeOOH}, \gamma-$ $\mathrm{FeOOH}$ and titanium. The difference in activity between $\alpha$ - and $\gamma-\mathrm{FeOOH}$ is about one order of magnitude. Since the equilibrium potential for hypochlorite reduction is highly positive (1.07 V vs. $\mathrm{Ag} / \mathrm{AgCl}, 70 \mathrm{mM}$ hypochlorite and $\mathrm{pH}=11$ ), the standard rate constants obtained by the fitting are afflicted with large errors and it is therefore more useful to compare the current density at constant potential. The Tafel slopes, transfer coefficients and the current densities at $-0.6 \mathrm{~V}$ vs. $\mathrm{Ag} / \mathrm{AgCl}$ are given in Table 2.

\section{$\mathrm{Cr}_{2} \mathrm{O}_{3}$ and $\mathrm{Cr}(\mathrm{OH})_{3}$}

Polarization curves were also recorded to evaluate the hypochlorite reduction on $\mathrm{Cr}_{2} \mathrm{O}_{3}$ and $\mathrm{Cr}(\mathrm{OH})_{3}$ deposited on titanium, Fig. 5. It is clearly demonstrated that the hypochlorite reduction is blocked in the presence of $\mathrm{Cr}_{2} \mathrm{O}_{3}$ and $\mathrm{Cr}(\mathrm{OH})_{3}$ on the surface. Experiments with different electrode rotation rates and different concentration of hypochlorite in solution were made but the response remained the same, clearly showing that hypochlorite is not reduced on electrodeposited $\mathrm{Cr}_{2} \mathrm{O}_{3}$ or $\mathrm{Cr}(\mathrm{OH})_{3}$.

Table 1 EDX

characterization of electrodeposited $\mathrm{Cr}(\mathrm{III})$ species on Ti substrate

\begin{tabular}{lll}
\hline Element/at\% & $\mathrm{Cr}_{2} \mathrm{O}_{3}$ & $\mathrm{Cr}(\mathrm{OH})_{3}$ \\
\hline $\mathrm{Ti}$ & 2 & 15 \\
$\mathrm{Cr}$ & 34 & 20 \\
$\mathrm{O}$ & 51 & 55 \\
Impurities $^{\mathrm{a}}$ & 12 & 9 \\
Cr:O & $2: 3$ & $1: 3$ \\
\hline
\end{tabular}

${ }^{\text {a }}$ Elements present in the electrodeposition electrolyte such as $\mathrm{C}, \mathrm{F}$ or $\mathrm{Si}$

\section{Calculations}

\section{Adsorption of Chloride}

The molecular orbital diagram of $\mathrm{ClO}^{-}$consists of bonding and anti-bonding orbitals with contributions from the $2 p$ orbitals on $\mathrm{O}$ and $3 p$ orbitals on $\mathrm{Cl}$. The remaining molecular orbitals are mainly constituted by orbitals from either $\mathrm{O}$ or $\mathrm{Cl}$ and are considered non-bonding in the molecule. All bonding and non-bonding orbitals are filled with electrons. Thus, in the reduction of the hypochlorite anion, the first electron will go into the anti-bonding orbital and hence the bond between $\mathrm{Cl}$ and $\mathrm{O}$ will split. In the second electron transfer, chloride ions are formed. The sequential reactions can be written:

$\mathrm{H}-\mathrm{O}-\mathrm{H}^{\cdots} \mathrm{OCl}+\mathrm{OCl}^{-} \rightarrow \mathrm{Cl}_{a d s}+2 \mathrm{OH}^{-}$

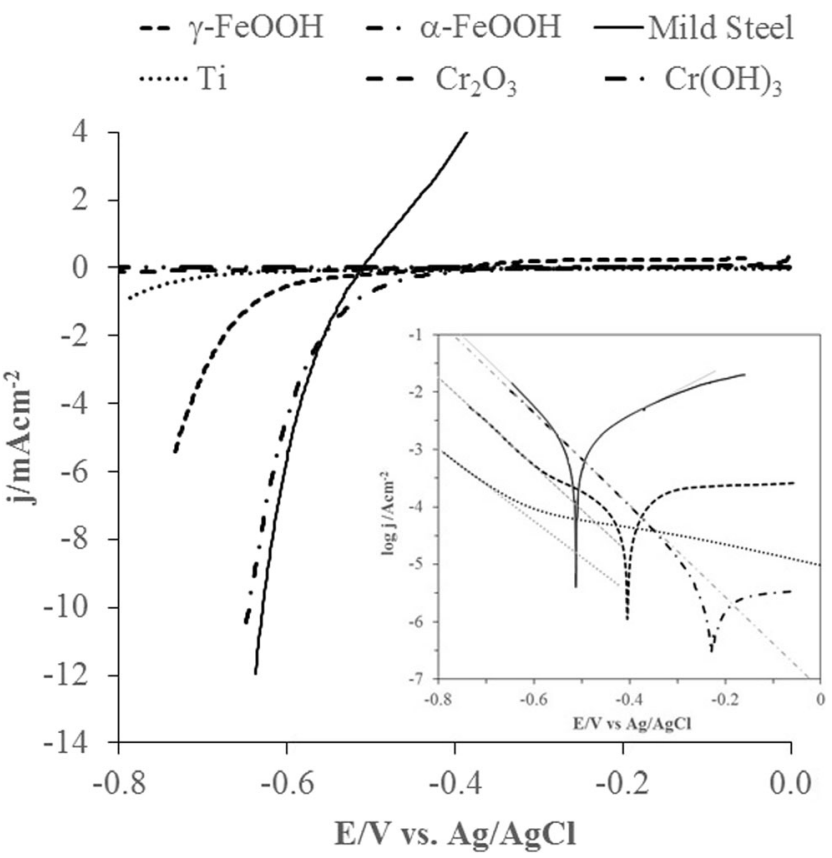

Fig. 5 Linear sweeps of hypochlorite reduction at different substrates in $0.2 \mathrm{M} \mathrm{Na}_{2} \mathrm{SO}_{4}, \mathrm{pH} 11$. In the inset, the logarithm of the current density is plotted as a function of potential for Ti, $\alpha$ - and $\gamma-\mathrm{FeOOH}$, and mild steel as substrates. The grey lines show the fittings to a one electron transfer reduction. For mild steel also an anodic reaction was included in the simulation. Sweep rate $5 \mathrm{mVs}^{-1}$ and rotation rate $3000 \mathrm{rpm}$ 
Table 2 Kinetic data for hypochlorite reduction. $\left[\mathrm{ClO}^{-}\right]=70 \mathrm{mM}$, $\mathrm{pH}=11$

\begin{tabular}{llll}
\hline & $\begin{array}{l}\mathrm{j} / \mathrm{mAcm}^{-2} \\
\text { at }-0.6 \mathrm{~V}\end{array}$ & $\alpha$ & Slope $/ \mathrm{mVdec}^{-1}$ \\
\hline $\mathrm{Ti}$ & 0.05 & 0.37 & 158 \\
Mild Steel & 4.27 & 0.47 & 125 \\
$\alpha-\mathrm{FeOOH}$ & 3.98 & 0.47 & 124 \\
$\gamma-\mathrm{FeOOH}$ & 0.46 & 0.45 & 130 \\
\hline
\end{tabular}

$C l_{a d s}+e^{-} \rightarrow C l^{-}(a q)$

assuming that the hypochlorite anion form hydrogen bonded complexes in solution. Hydrogen bonding between the $\mathrm{ClO}$ radical and water has been studied with DFT calculations and different hydrogen bonded complexes have been suggested $[39,40]$. For the anion, it is likely that hydrogen on the water molecule will bind loosely to oxygen in hypochlorite and upon splitting of the $\mathrm{Cl}-\mathrm{O}$ bond an adsorbed $\mathrm{Cl}$ atom is formed together with two hydroxide ions. This scenario was the starting point for the theoretical description of hypochlorite reduction on oxide surfaces.

Reaction (3) was used as descriptor to investigate the adsorption of chloride on iron and chromium oxide,

$$
\mathrm{TM}-\mathrm{Cl}+\mathrm{H}_{2} \mathrm{O} \leftrightarrow \mathrm{TM}-\mathrm{OH}+\mathrm{HCl}
$$

where TM stands for transition metal, in this case Fe or $\mathrm{Cr}$ displacing $\mathrm{Mg}$ in the $\mathrm{MgO}_{\mathrm{y}}(\mathrm{OH})_{\mathrm{z}}$ test rig, Fig. 6 . Solvent effects are included indirectly through the Born-Haber cycle, Fig. 7. The results are given in Table 3 for $\mathrm{Fe}(\mathrm{III})$ and $\mathrm{Cr}(\mathrm{III})$. The adsorption energy of chloride on $\mathrm{Fe}(\mathrm{III})$ and $\mathrm{Cr}(\mathrm{III})$ is very similar. Thus, the different behaviour of iron and chromium oxides towards hypochlorite reduction cannot be explained solely by differences in the relative adsorption energy for the chloride intermediate.

\section{Mechanism of Hypochlorite Reduction}

Considering the very similar relative binding energies of TM$\mathrm{Cl}$ the full reduction cycle was studied. The assumed mechanism proceeds through three purely chemical steps comprising the adsorption of $\mathrm{OCl}$, the splitting into $\mathrm{TM}=\mathrm{O}$ and $\mathrm{TM}-\mathrm{Cl}$ and the release of $\mathrm{HCl}$. This is followed by the electrochemical recovery of the catalyst, see Fig. 8 . The first step is the replacement of a $\mathrm{TM}-\mathrm{OH}$ group with $\mathrm{HOCl}$ under formation of a TM-OCl group and a water molecule (a). This is followed by breaking of the $\mathrm{Cl}-\mathrm{O}$ bond and release of $\mathrm{H}_{2} \mathrm{O}$ from the adjacent $\mathrm{TM}-\mathrm{OH}$ group, which results in the $\mathrm{TM}-\mathrm{Cl}$ and $\mathrm{TM}=\mathrm{O}$ intermediates (b). The reaction proceeds through a purely chemical step, assuming that the trans-standing $\mathrm{OH}$ group donates its hydrogen to the released water molecule. Accordingly, the oxidation state of the TM-Cl group is increased from $+\mathrm{III}$ to $+\mathrm{IV}$. Having splitted the $\mathrm{O}-\mathrm{Cl}$ bond, the catalytic sites need to be recovered. This is assumed to happen by dissolution of $\mathrm{Cl}^{-}$combined with the adsorption of $\mathrm{OH}^{-}$ (c). This reaction is approximately thermoneutral for both $\mathrm{Cr}(\mathrm{IV})-\mathrm{Cl}$ and $\mathrm{Fe}(\mathrm{IV})-\mathrm{Cl}$. It is followed by the reduction of the TM sites $(\mathrm{d}, \mathrm{e})$. Both reduction steps are strongly endothermic versus $\mathrm{TyrO}^{*} / \mathrm{TyrOH}$ for the $\mathrm{Cr}$ and $\mathrm{Fe}$ oxides. However, considering the high positive potential of this reference reaction the two reduction steps can be expected to proceed without major problems at the potentials relevant for the hydrogen evolution reaction. Overall this reaction cycle is energetically feasible on both iron and chromium with negligible differences in energy. This is also the case for other possible reaction cycles involving $\mathrm{Fe}(\mathrm{III}) / \mathrm{Fe}(\mathrm{IV})$ and $\mathrm{Cr}(\mathrm{III}) /$ $\mathrm{Cr}(\mathrm{IV})$. Thus, according to the assumed mechanism, it is clearly demonstrated that the active site, whether Fe(III) or $\mathrm{Cr}$ (III), is not responsible for the dramatic differences in reduction kinetics found experimentally.

\section{Discussions}

In the history of the chlorate process, different explanations for the role of chromate have been suggested, such as buffering ability in solution, formation of a thin layer on the cathode that prevents hypochlorite reduction and as corrosion inhibitor for the mild steel cathodes [4, 7-17]. The nature of the film formed by reduction of $\mathrm{Cr}(\mathrm{VI})$ is still not completely known, even though in situ characterization have suggested $\mathrm{Cr}(\mathrm{OH})_{3}$. $\mathrm{xH}_{2} \mathrm{O}$ on $\mathrm{Pt}[6]$ and both $\mathrm{Cr}(\mathrm{OH})_{3}[6,11]$ and $\mathrm{Cr}_{2} \mathrm{O}_{3}[41]$ on gold. In the present work, we chose to study model systems such as $\mathrm{Cr}_{2} \mathrm{O}_{3}$ and $\mathrm{Cr}(\mathrm{OH})_{3}$ electrodeposited on titanium. Both films were shown to block hypochlorite reduction in alkaline solution, relevant for the surface environment during production. It appears that irrespective of the composition of the chromium film it is extremely efficient in blocking the hypochlorite reduction. Here, we will focus on hypochlorite reduction and discuss the results in the context of acid-base properties of the oxide surfaces and hypochlorite in solution,

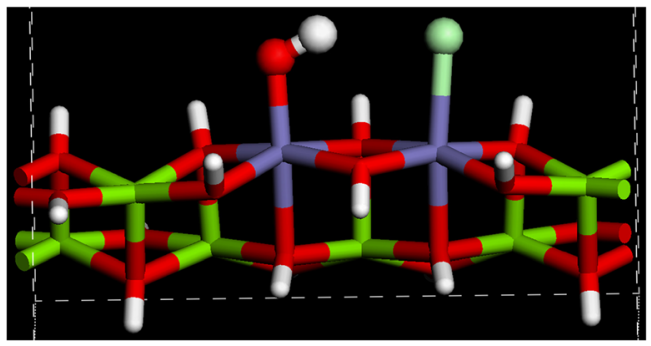

Fig. 6 Two dimensional test rig consisting of a $\mathrm{MgO}_{\mathrm{x}}(\mathrm{OH})_{\mathrm{z}}$ backbone with two adjacent $\mathrm{Mg}$ ions exchanged for other transition metal ions (TM). TM-Cl and TM-OH are explicitly shown in the figure 
Fig. 7 Born-Haber cycle for inclusion of solvent effects on the adsorption of chloride on transition metal oxides. The dissolution energies were taken from experiments $[52,53]$

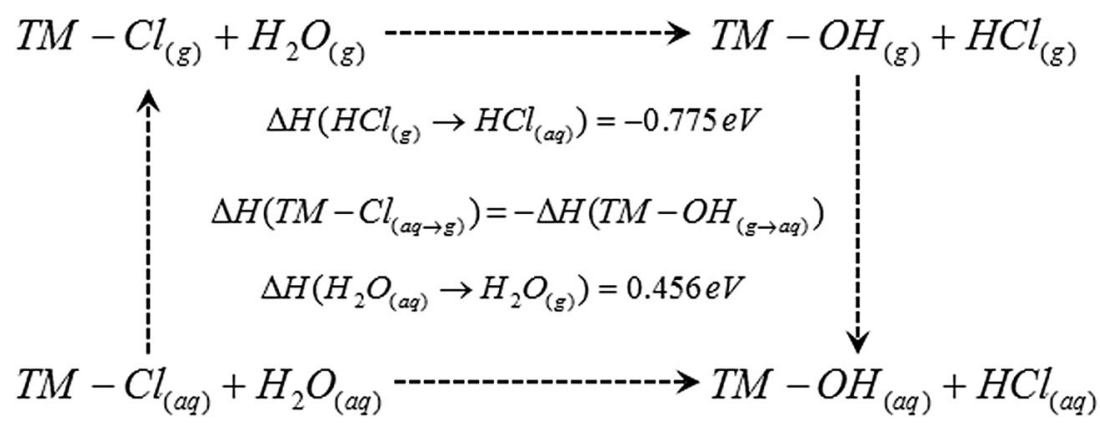

electrocatalytic ability and electronic properties of the oxide films used as model substances. These aspects can help in discriminating between the prevailing explanations of the beneficial effects of chromate on the energy efficiency of the chlorate process.

\section{Acid-Base Properties}

In aqueous solution oxides have acid-base properties and the $\mathrm{pH}$ of zero charge (pzc) depends on the nature of the oxide and can be calculated from the formal charge of the metal and the covalence of the bonding [42]. Experimentally determined values for the pzc differ depending on electrolyte composition and method used to determine the surface equilibrium constants. Kosmulski has done comprehensive compilations of the pzc for different oxides [43-46] and reports pzc $=8.6$ \pm 0.8 for synthetic goethite, $7.1 \pm 0.7$ for synthetic lepidocrocite [46], $7.9 \pm 1.2$ for $\mathrm{Cr}(\mathrm{OH})_{3}$ and $7.0 \pm 1.6$ for $\mathrm{Cr}_{2} \mathrm{O}_{3}$ [47]. The general acid base reaction for a trivalent oxide can be written [48]:

$\equiv \stackrel{I I I}{M}-\mathrm{OH}_{2}^{1 / 2} \leftrightarrow \stackrel{I I I}{M}-\mathrm{OH}^{-1 / 2}+H^{+}$

The $p K_{a}$ of this reaction is also equal to pzc for the oxide. This means that at $\mathrm{pH}=11$ all surfaces are negatively charged.

The $p K_{a}$ of hypochlorous acid is 7.53 , which means that the hypochlorite anion is dominating at $\mathrm{pH} 11$. The reduction of the negatively charged hypochlorite ion thus takes place at a negatively charged surface and will in part be hampered by transport of the anions to the surface and an adverse potential gradient [17]. It was early shown for chlorate cells that reduction of hypochlorite is controlled by diffusion to the electrode [8]. In order to investigate the kinetics of hypochlorite reduction, mass

Table 3 Adsorption energies for chloride according to reaction $\mathrm{TM}-\mathrm{Cl}+\mathrm{H}_{2} \mathrm{O} \rightarrow \mathrm{TM}-$ $\mathrm{OH}+\mathrm{HC}$

\begin{tabular}{lll}
\hline TM & Oxidation state & $\begin{array}{l}\text { Test rig } \\
\text { Energy/eV }\end{array}$ \\
\hline $\mathrm{Fe}$ & III & 0.45 \\
$\mathrm{Cr}$ & III & 0.48 \\
\hline
\end{tabular}

transport limitation was minimized by using a rotating disc electrode. No rotation speed dependence was however observed and the kinetic analyses were therefore made at constant rotation. In the present paper, it was clearly demonstrated experimentally that chromium oxide and hydroxide electrochemically deposited on titanium substrate completely block the reduction of hypochlorite ions, while on $\alpha$ - and $\gamma$ - FeOOH the reduction readily occurs. The adverse potential gradient applies to all surfaces but may depend on the morphology of the layer. For a flat surface in high conducting electrolyte the effect is small but for porous surfaces it can be significant. However, the different activities for hypochlorite reduction described above, rule out the adverse potential gradient as the only explanation for the lack of hypochlorite reduction on the chromium films. It is interesting to note that the adverse potential gradient will apply also to the reduction of the divalent chromate ion and the concept has been used to explain the thickness of the in situ formed chromium layer [17].

\section{Electrocatalytic Properties}

The rate limiting step in the reduction of hypochlorite on $\alpha$ and $\gamma$-FeOOH as well as on mild steel and titanium seems to be the first electron transfer. This is based on the Tafel slope obtained by polarization measurement. Since the electron will go into an anti-bonding orbital the bond between $\mathrm{Cl}$ and $\mathrm{O}$ will break. The proximity of water molecules through hydrogen bonding may facilitate the formation of hydroxide ions in solution leaving the chloride adsorbed on the surface. The adsorption energy for chloride on $\mathrm{Fe}$ (III) and $\mathrm{Cr}$ (III) was found to be similar and show that both iron and chromium should support the reduction reaction, in contrast with the experimental results. This is an interesting finding since it clearly demonstrates that the electrocatalytic properties per se are not responsible for the different behaviour towards hypochlorite reduction on iron and chromium oxide.

\section{Electronic Conduction}

The electrode material also has a large impact on the performance of the $\operatorname{Cr}$ (III) hydroxide film. For example a steel 
Fig. 8 Reaction cycle and reaction energies for reduction of hypochlorite on transition metal oxides

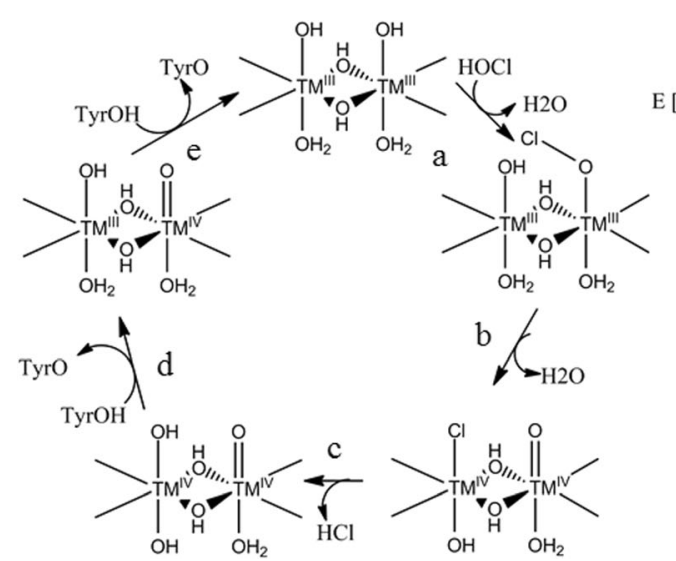

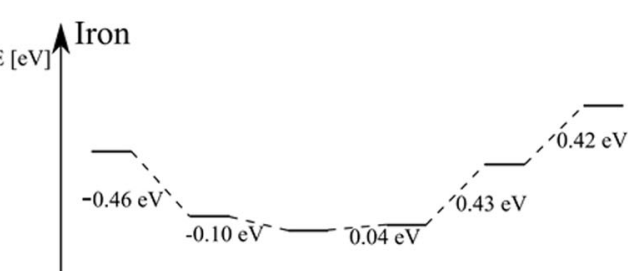

Chromium

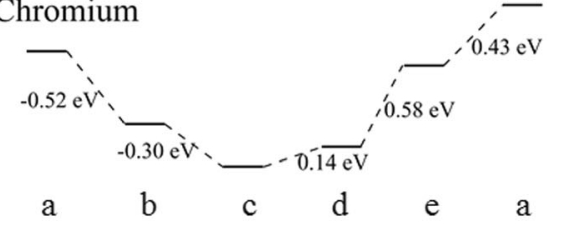

cathode requires much higher chromate concentration in the electrolyte to reach a high current efficiency $(1-5 \mathrm{~g} / \mathrm{l})$ while a titanium electrode only needs trace levels to reach the same current efficiency [9]. On mild steel, it is expected that chromium will be built into the corrosion layer and thereby loses its blocking ability. In relation to this, a highly interesting aspect that has not been properly explored is the role of conduction in the deposited layers and the influence on the reduction kinetics. Iron oxy hydroxides and oxides are known to have n-type conduction and can readily support reduction reactions. For chromium oxide, the situation is more complex. It has been reported that thin passive layers formed on chromium metal in acidic media show n-type conduction and reduction reactions such as hydrogen evolution can thus readily take place $[49,50]$. However, deposited chromium oxide is known to have p-type conduction, i.e., reduction processes are suppressed. For mixed chromium and iron oxides, the conduction varies from p-type for chromium rich oxides to n-type for iron rich oxides [51]. For chromium rich oxides p-type properties are observed but with a change in the charge-carrier concentration and a shift in the flatband potentials to more positive values. As the iron content increases, an n-p transition takes place when the potential is made more positive [51]. As described above, it is expected that the surface film formed on steel cathodes in the chlorate process will be composed of a mixture of iron and chromium hydroxide. The semiconducting properties will change with the composition and the ability of promoting reduction of for example hypochlorite will increase with the iron content. This can possibly explain the need for using higher amounts of chromate addition for steel cathodes compared to non-corroding cathodes such as titanium or DSA.

\section{Conclusions}

The effect of substrate on the reduction of hypochlorite has been explored. The experimental results clearly demonstrated that:
- electrodeposited $\mathrm{Cr}_{2} \mathrm{O}_{3}$ and $\mathrm{Cr}(\mathrm{OH})_{3}$ films on titanium completely block hypochlorite reduction

- electrodeposited $\alpha$ - and $\gamma$-FeOOH films have the ability to reduce hypochlorite. Compared with non-corroded mild steel the activity is lower in the order mild steel $>\alpha-\mathrm{FeOOH}>\gamma-\mathrm{FeOOH}$

The theoretical calculations focused active site on the surface and the adsorption of chloride as an intermediate in the hypochlorite reduction reaction. The result showed no main differences in adsorption energy of chloride between iron (III) and chromium (III) in the oxide matrix. Also the stepwise energies involved in a reaction cycle where the active site is regenerated are very similar. These results clearly show that it is not the electrocatalytic activity that causes the dramatic difference in reduction behaviour found experimentally.

From the experimental and theoretical results obtained in the present paper and the general knowhow of the chlorate process it is suggested that a combination of the reduction of a negative ion, $\mathrm{ClO}^{-}$, and the semiconducting properties of the electrodeposited chromium oxide film explains the beneficial effect of chromate on energy efficiency in the chlorate process. As a consequence, at least these two aspects need to be considered in the search for replacement of chromate in the chlorate process.

Acknowledgments Financial support from the Swedish energy agency, 33280-1, and the Swedish research council, 621-2010-4035, is gratefully acknowledged. The authors would like to thank Nina Simic, Mats Wildlock and Johan Wanngård at Akzo Nobel Pulp and Performance Chemicals, Bohus, Sweden, for fruitful discussions.

Open Access This article is distributed under the terms of the Creative Commons Attribution 4.0 International License (http:// creativecommons.org/licenses/by/4.0/), which permits unrestricted use, distribution, and reproduction in any medium, provided you give appropriate credit to the original author(s) and the source, provide a link to the Creative Commons license, and indicate if changes were made. 


\section{References}

1. H. Vogt, J. Balej, J.E. Bennett, P. Wintzer, S.A. Sheikh, P. Gallone, S. Vasudevan, K. Pelin, Chlorine oxides and chlorine oxygen acids, in: Ullman's encyclopedia for industrial chemistry (Wiley-VHC Verlag, Weinheim, 2010)

2. F. Foerster, F. Jorre, Zur kenntniss der beziehungen der unterchlorigsauren salze zu den chlorsauren salzen. J Prakt Chem 59, 53-101 (1899)

3. Landin J (1897) Förfaringssätt vid framställning af klorater och perklorater, in: Swedish Patent no. SE8820, Sweden

4. E. Müller, Über ein elektrolytisches verfahren zur gewinnung der clor-, brom- und jodsauren salze der alkalien. Z Elektrochem 41, 469-473 (1899)

5. A. Ahlberg Tidblad, J. Mårtensson, In situ ellipsometric characterization of films formed by cathodic reduction of chromate. Electrochim Acta 42, 389-398 (1997)

6. A. Ahlberg Tidblad, G. Lindbergh, Surface analysis with esca and gd-oes of the film formed by cathodic reduction of chromate. Electrochim Acta 36, 1605-1610 (1991)

7. A. Cornell, G. Lindbergh, D. Simonsson, The effect of addition of chromate on the hydrogen evolution reaction and on iron oxidation in hydroxide and chlorate solutions. Electrochim Acta 37, 1873$1881(1992)$

8. L. Hammar, G. Wranglen, Cathodic and anodic efficiency losses in chlorate electrolysis. Electrochim Acta 9, 1 (1964)

9. K.L. Hardee, K.L. Mitchell, The influence of electrolyte parameters on the percent oxygen evolved from a chlorate cell. J Electrochem Soc 136, 3314-3318 (1989)

10. M.M. Jaksic, Mutual effect of current density, $\mathrm{pH}$, temperature, and hydrodynamic factors on current efficiency in the chlorate cell process. J Electrochem Soc 121, 70-79 (1974)

11. G. Lindbergh, D. Simonsson, The effect of chromate addition on cathodic reduction of hypochlorite in hydroxide and chlorate solutions. J Electrochem Soc 137, 3094-3099 (1990)

12. G. Lindbergh, D. Simonsson, Inhibition of cathode reactions in sodium hydroxide solution containing chromate. Electrochim Acta 36, 1985-1994 (1991)

13. M. Spasojevic, N. Krstajic, M. Jaksic, Electrocatalytic optimization of faradaic yields in the chlorate cell process. Surf Technol 21, 1926 (1984)

14. M. Spasojevic, N. Krstajic, P. Spasojevic, L. Ribic-Zelenovic, Modelling current efficiency in an electrochemical hypochlorite reactor. Chem Eng Res Des 93, 591-601 (2014)

15. M. Spasojevic, L. Ribic-Zelenovic, P. Spasojevic, B.Z. Nikolic, Current efficiency in the chlorate cell process. J Serb Chem Soc 76, 677-688 (2014)

16. I. Taniguchi, T. Sekine, The influence of chromate addition on the cathodic reduction of hypochlorite ion. Denki Kagaku 43, 201-208 (1975)

17. C. Wagner, The cathodic reduction of anions and the anodic oxidation of cations. J Electrochem Soc 101, 181-184 (1954)

18. REACH, Annex xiv, Commision regulation (EU), No 348/2013 (2013)

19. J. Gustavsson, G. Li, C. Hummlegård, J. Bäckström, A. Cornell, On the suppression of cathodic hypochlorite reduction by electrolyte additions of molybdate and chromate ions. J Electrochem Sci Eng 2, 185-198 (2012)

20. J. Gustavsson, L. Nylén, A. Cornell, Rare earth metal salts as potential alternatives to $\mathrm{Cr}(\mathrm{VI})$ in the chlorate process. J Appl Electrochem 40, 1529-1536 (2010)

21. M. Li, Z. Twardowski, F. Mok, N. Tam, Sodium molybdate-a possible alternate additive for sodium dichromate in the electrolytic production of sodium chlorate. J Appl Electrochem 37, 499-504 (2007)
22. L. Nylén, J. Gustavsson, A. Cornell, Cathodic reactions on an iron rde in the presence of y(iii). J Electrochem Soc 155, E136-E142 (2008)

23. Rosvall M, Hedenstedt K, Sellin A, Gustavsson J, Cornell A (2012) Activation of cathode, US Patent, 2012/0061252

24. Hedenstedt K, Edvinsson Albers R (2013) Electrolyte process, US Patent, 2013/0292261

25. L. Martinez, D. Leinen, F. Martín, M. Gabas, J.R. Ramos-Barrado, E. Quagliata, E.A. Dalchieleb, Electrochemical growth of diverse iron oxide $\left(\mathrm{Fe}_{3} \mathrm{O}_{4}, \mathrm{a}-\mathrm{FeOOH}\right.$, and $\left.\mathrm{g}-\mathrm{FeOOH}\right)$ thin films by electrodeposition potential tuning. J Electrochem Soc 154, D126-D133 (2007)

26. M. Aguilar, E. Barrera, M. Palomar-Pardav, L. Huerta, S. Muhl, Characterization of black and white chromium electrodeposition films: surface and optical properties. J Non-Cryst Solids 329, 31 38 (2003)

27. S.J. Clark, M.D. Segall, C.J. Pickard, P.J. Hasnip, M.J. Probert, K. Refson, M.C. Payne, First principles methods using castep. Z Kristallogr 220, 567-570 (2005)

28. Materials studio release 5.0, 2009

29. J.P. Perdew, K. Burke, M. Ernzerhof, Generalized gradient approximation made simple. Phys Rev Lett 77, 3865-3868 (1996)

30. D. Vanderbilt, Soft self-consistent pseudopotentials in a generalized eigenvalue formalism. Phys Rev B Condens Matter 41, 7892-7895 (1990)

31. M. Busch, E. Ahlberg, I. Panas, Hydroxide oxidation and peroxide formation at embedded binuclear transition metal sites; $\mathrm{TM}=\mathrm{Cr}$, Mn, Fe, Co. PCCP 13, 15062-15068 (2011)

32. M. Busch, E. Ahlberg, I. Panas, Electrocatalytic oxygen evolution from water on a $\mathrm{Mn}(\mathrm{III}-\mathrm{V})$ dimer model catalyst - a DFT perspective. PCCP 13, 15069-15076 (2011)

33. A. Harriman, Further comments on the redox potentials of tryptophan and tyrosine. J Phys Chem A 91, 6102-6104 (1987)

34. M. Busch, E. Ahlberg, I. Panas, Water oxidation on $\mathrm{MnO}_{\mathrm{x}}$ and $\mathrm{IrO}_{\mathrm{x}}-$ why similar performance? J Phys Chem C 117, 288-292 (2013)

35. M. Busch, E. Ahlberg, I. Panas, Validation of binuclear descriptor for mixed transition metal oxide supported electrocatalytic water oxidation. Catal Today 202, 114-119 (2013)

36. P. Steegstra, M. Busch, I. Panas, E. Ahlberg, Revisiting the redox properties of hydrous iridium oxide films in the context of oxygen evolution. J Phys Chem C 117, 20975-20981 (2013)

37. M. Stratmann, K. Hoffmann, In-situ mössbauer spectroscopic study of reactions within rust layers. Corros Sci 29, 1329-1352 (1989)

38. M. Aguila-Sánchez, M. Palomar-Pardavé, M. Romero-Romo, M.T. Ramírez-Silva, E. Barrera, B.R. Scharifker, Electrochemical nucleation and growth of black and white chromium deposits onto stainless steel surfaces. J Electroanal Chem 647, 128-132 (2010)

39. J.S. Francisco, S.P. Sander, Existence of a chlorine oxide and water $\left(\mathrm{ClO}^{*} \mathrm{H}_{2} \mathrm{O}\right)$ radical complex. J Am Chem Soc 117, 9917-9918 (1995)

40. H. Fu, Z. Zhou, X. Zhou, Hydrogen bonding between chlorine oxide and water $\left(\mathrm{H}_{2} \mathrm{O} * \mathrm{ClO}\right)$ radical complex. Chem Phys Lett 382, 466-474 (2003)

41. J.J. Hatch, A.A. Gewirth, Potential dependent chromate adsorption on gold. J Electrochem Soc 156, D479-D502 (2009)

42. T. Hiemstra, W.H. van Riemsdijk, G.H. Bolt, Multisite proton adsorption modeling at the solid/solution interface of (hydr)oxides: a new approach. J Colloid Interface Sci 133, 91-104 (1989)

43. M. Kosmulski, The $\mathrm{pH}$-dependent surface charging and the points of zero charge. J Colloid Interface Sci 253, 77-87 (2002)

44. M. Kosmulski, pH-dependent surface charging and points of zero charge II. Update. J Colloid Interface Sci 275, 214-224 (2004)

45. M. Kosmulski, Ph-dependent surface charging and points of zero charge III. Update. J Colloid Interface Sci 298, 730-741 (2006) 
46. M. Kosmulski, Compilation of pzc and iep of sparingly soluble metal oxides and hydroxides from literature. Adv Colloid Interface Sci 152, 14-25 (2009)

47. A.E. Onjia, S.K. Milonjic, D. Cokesa, M. Comor, N. Miljevic, Characterization of colloidal chromia particles obtained by forced hydrolysis. Mater Res Bull 38, 1329-1339 (2003)

48. J.-F. Boily, J. Lützenkirchen, O. Blamès, J. Beattie, S. Sjöberg, Modeling proton binding at the goethite (aFeOOH)-water interface. Colloids Surf A Physicochem Eng Asp 179, 11-27 (2001)
49. J.P. Popić, D.M. Dražić, Electrochemistry of active chromium part II. Three hydrogen evolution reactions on chromium in sulfuric acid. Electrochim Acta 49, 4877 (2004)

50. P.C. Searson, R.M. Latanision, A photoelectrochemical study of the passive film on chromium. Electrochim Acta 35, 445-450 (1990)

51. H. Asteman, E. Ahlberg, J.-E. Svensson, Electric properties of alpha-Fe2O3, $\mathrm{Cr} 2 \mathrm{O} 3$ and alpha-(Cr, Fe)2O3 and their relevance to corrosion. Electrochem Soc 99-38, 17-25 (2000)

52. CRC handbook of chemistry and physics, 85 th ed., in: D.R. Lide (Ed.), CRC Press, Boca Raton, 2004

53. S.R. Gunn, L.R. Green, Heat of solution of hydrogen chloride. J Chem Eng Data 8, 180 (1963) 